\title{
Biometric notes on Tupiperla Froehlich (Plecoptera, Gripopterygidae)
}

\section{Claudio G. Froehlich ${ }^{1}$}

\begin{abstract}
In Tupiperla Froehlich, 1969, the presence or the absence of the S cross-vein in the forewings are useless both as a generic and as a specific character. The relative antenna length and the number of cercomeres may be useful in discriminating between species.

KEY WORDS. Plecoptera, Tupiperla, wings, s cross-vein, antenna length, cercomeres
\end{abstract}

During taxonomic work on Tupiperla Froehlich, 1969 enough material was accumulated to make possible a quantitative assessment of a few meristic and continuous characters used in the taxonomy of the genus (FROEHLICH 1999). These are the presence or absence of the $\underline{s}$ cross-vein (cross-vein between the branches of the Rs fork) in the forewings, the relative length of the antennae and the number of cercomeres. ILLIES (1963), in his revision of the South American Gripopterygidae, used these characters, among others, in his definitions of the genera. Tupiperla (sub nom. Paragripopteryx) was considered to have antennae longer that the body, reaching wing tips in repose, Rs to be forked with (mostly) a cross-vein between the branches and to have cerci with ca. 20 cercomeres. Except for the Rs fork, the other characters vary within the genus and, to a lesser extent, within individual species. Throughout the genus, the presence of the $\underline{s}$ cross-vein is size-dependent, smaller species tending to lack it and larger species to have it. Within most species there is also a trend for larger specimens to have the s cross-vein. As regards the relative antenna length and the number of cercomeres, the relation to size is more erratic, as is shown below. For data on these characters for individual species, see FROEHLICH (1999).

\section{MATERIAL AND METHODS}

For the assessment of the occurrence of the $\mathrm{s}$ cross-vein in the forewings (in the hindwings it is rarely present), 504 wings of males and 503 of females over all 10 species studied in FroeHLich (1999), were examined. A graph plotting presence or absence of the s cross-vein against the length of the forewing, was made. Regarding the length of the antennae, the ratio of the median length of the antenna to the forewing mean length was plotted against the mean forewing length for each species. The median length was used instead of the mean because the median is less sensitive to the occasional loss of some antennomeres. For the number of cercomeres, their median number was plotted against the mean forewing length for each species.

Standard statistical procedures (t-test, correlation) were employed.

1) Departamento de Biologia, Faculdade de Filosofia Ciências e Letras, Universidade de São Paulo. 14040-901 Ribeirão Preto, São Paulo, Brasil. Bolsista do CNPq.

E-mail: cgfroeh@usp.br 


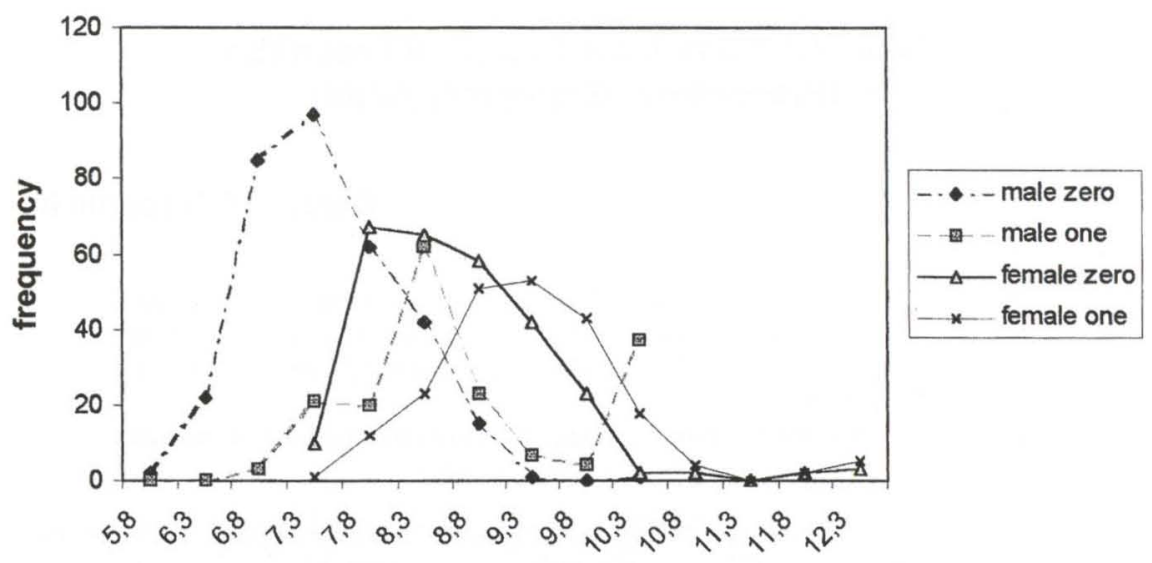

forewing length, $\mathrm{mm}$

Fig. 1. Tupiperla, frequency polygons for the $s$ cross-vein. (male zero, female zero: specimens lacking an s cross-vein; male one, female one: specimens having an s cross-vein).

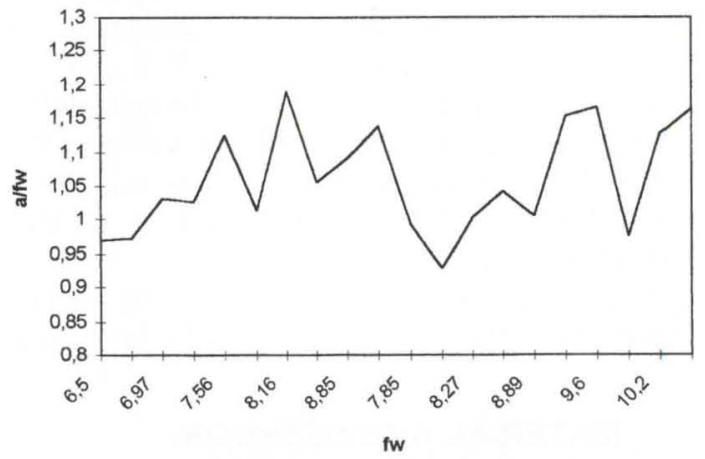

Fig. 2. Tupiperla, relation of the relative antenna length to the forewing length. (fw) Forewing length, milimeter; (a/fw) antenna length/forewing length.

\section{RESULTS AND DISCUSSION}

Figure 1 shows the relation of the presence of an $\mathrm{S}$ cross-vein to wing size. It may be seen that for both males and females an s cross vein may be present or absent in most size classes, but that there is a clear size dependence, as larger wings tend to have the cross-vein. Within a species, the values are very scattered, resulting in low statistical discrimination. For example, for T. illiesi Froehlich, 1999 males, for which a large number of wings were available $(\mathrm{N}=94)$, the average forewing length for zero $\mathrm{s}$ is $7.49 \mathrm{~mm}$, for one $\mathrm{s}$ is $7.63 \mathrm{~mm}$, but the t-test result is not significant $(\mathrm{p}=0.08)$. Likewise, for T. eleonorae (Froehlich, 1999) females, the values are, respectively, $141,8.26$ and $8.41(\mathrm{p}=0.10)$. These results indicate that the presence of an \$ cross-vein in the forewings, due to its dispersion and size-dependence, should not be used either as a generic or as a specific character. 

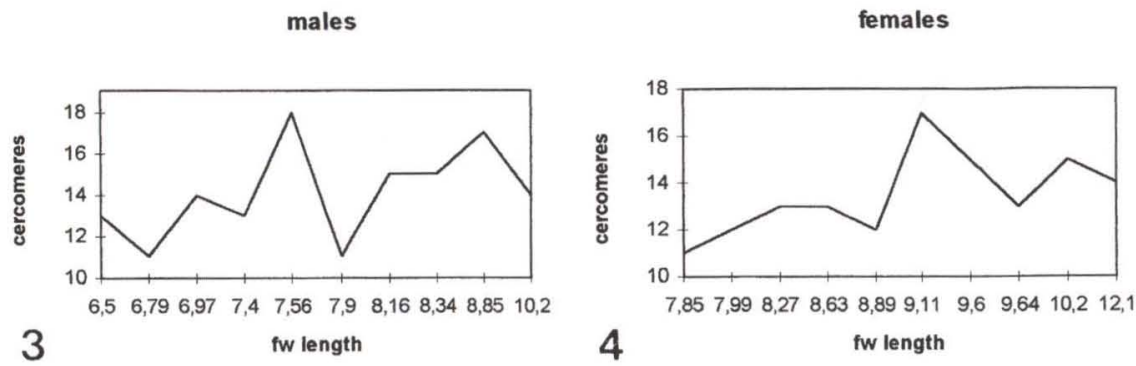

Figs 3-4. Tupiperla, relation of the cercomere number to the forewing length in milimeter. (3) Males; (4) females.

Figure 2 shows the relation between the relative length of the antenna against the forewing length for both sexes. The graphs for each sex show a similar trend. Although there is a significant correlation between the variables $(\mathrm{N}=10$ species, $\mathrm{r}=0.565, \mathrm{p}<0.01$ ), the curve is jagged, indicating that the antenna length may be used as an ancillary character in discriminating between species of similar size.

Figures 3 and 4 show, for each sex, the relation of the cercomere number to forewing length. The separation by sex is necessary because females are larger than males, but the median number of cercomeres is the same or smaller. Both curves show a slight trend of increasing cercomere numbers against the forewing length, but the correlation is not significant for both sexes $(\mathrm{N}=10$ species; $r=0.331$ for males and $r=0.464$ for females). As in the case of the relative antennal length, the curves are jagged. These results indicate that this character may be useful in separating species of similar size but of contrasting cercomere numbers.

ACKNOWLEDGEMENTS. To CNPq (Conselho Nacional de Desenvolvimento Científico e Tecnológico) for a research fellowship (301247/96-0).

\section{REFERENCES}

Froehlich, C.G. 1999. Seven new species of Tupiperla (Plecoptera: Gripopterygidae) from Brazil, with a revision of the genus. Stud. Neotrop. Fauna Environ. 33: 19-36.

ILlIES, J. 1963. Revision der südamerikanische Gripopterygidae (Plecoptera). Mitt.

Schweizer. Ent. Ges. 36: 145-248. 